\title{
OPEN
}

\section{Introduction: Not Another Book about Interdisciplinarity}

\begin{abstract}
In the introduction, we introduce our monograph, Rethinking Interdisciplinarity, as a report from the interdisciplinary field - and an account of our own attempts to work and live across the social sciences and neurosciences. The introduction sets out the core goal of the volume, which is to give a sense, beyond bland encouragements, of what actually goes into, and what goes on in, interdisciplinary projects. The introduction sets out the core reasons that we have pursued interdisciplinary research, with our collaborators, across the neurosciences and social sciences but it also establishes our view that interdisciplinarity is nonetheless a problem, or a set of problems, to be analysed in its own right.
\end{abstract}

Keywords: entanglement; interdisciplinarity; neuroscience; social science

Callard, Felicity and Des Fitzgerald. Rethinking Interdisciplinarity across the Social Sciences and Neurosciences. Basingstoke: Palgrave Macmillan, 2015. DOI: $10.1057 / 9781137407962.0003$. 
A few years ago, we were at an interdisciplinary workshop for researchers who were broadly interested in the intersections between the neurosciences, the humanities, and the social sciences. We had arrived, separately, at the workshop, as two social scientists (FC as a cultural and health geographer; DF as a sociologist) who had been working on projects that were more-or-less about some aspect of the neurosciences, psychology, or psychiatry - but who had also lately begun to suspect, quite independently of one another, that we might be able to make more interesting interventions by somehow collaborating with people in those sciences, rather than simply scrutinizing them, from the outside, as objects of historical, cultural, or sociological attention. We didn't know one another at that point, and we found ourselves on the margins of the same group - where we fell into conversation about how we had come to be engaged with the life sciences, about our hopes for the meeting, and about our anxieties and excitement vis-à-vis actually doing something more experimentally interdisciplinary. Central to our conversation was a shared sense that the conventional theoretical assumptions and methodological manoeuvres that we had each inherited from our own discipline (geography and sociology, respectively), and which were supposed to help us understand the biosciences, were, in fact, quite inadequate to a moment in which those same sciences seemed ever more richly and capaciously social in both their orientation and their practice.

And so there we were, feeling somewhat at sea both socially and epistemologically, when one of the organizers of the meeting approached us, asking whether we were having a good conversation, and whether we could see any interdisciplinary opportunities. Uh, yes, we could! There were certainly all sorts of crossovers between our different geographical and sociological inheritances; we were sure that there were various ways in which we might develop an interdisciplinary collaboration. All seemed well. But then it became clear that we had not yet hooked up with any neuroscientists. We had thought, then, that because the two of us were from two distinct disciplines, that our incipient collaboration would already count as 'interdisciplinary'. But it appeared that it was a bit of a problem: we were not, as it turned out, having an interdisciplinary conversation with one another at all. In fact, what 'interdisciplinarity' meant in this space, despite some loose talk, was actually something quite specific - and this specific thing did not include the coming together of a geographer and a sociologist. It essentially meant a neuroscientist plus some others. The implicit address to all those of us (philosophers, bioethicists, lawyers, 
psychologists, social scientists) in the room who were not neuroscientists was: find yourself a neuroscientist; design an experiment together; allow your own expertise to nuance some conceptual part of the design; and then get out of the way. This, it became increasingly clear as the workshop moved into its second, and then its third day, was the model of interdisciplinarity on offer.

Well, the two of us did, eventually, find a neuroscientist - and we ended up working together on methodological and substantive issues of interest to each of us. And so, maybe the organizer was right in adjudicating how best to orient people towards putting together collaborative projects. Still, and albeit only in retrospect, this was an early clue that there was a lot more going on beneath the surface of these interdisciplinary attempts to bring together neuroscientists, social scientists, and humanities scholars than either of us had imagined. In fact, beneath the frictionless imaginary of equably co-labouring humanities scholars, scientists, and social scientists - each with her own, dedicated tasks to perform - heterogeneous organizations, individuals, and technologies were creating a very specific, and surprisingly powerful, intellectual space. This space, moreover, for all the talk about its openness and creativity, had some sharp edges - as well as what we increasingly came to identify as surprisingly conservative inheritances. Over the years that followed that workshop, we continued to work across the social sciences and neurosciences, separately and together, and usually with others too. This was not, at least initially, because we were interested in 'interdisciplinarity' in its own right. Rather, we were convinced, as many others have been before us (e.g. Rose 2013), that one could no longer talk about human social life, in all its complexity, contest, history, and nuance, as if that life were not also threaded through the biological propensities of an assemblage of human animals (as well as non-human animals, and indeed non-humans in general). And vice versa: that new, sophisticated, and nuanced tools for taking - and analysing - biological measures (it was measures of brain function that especially captured our attention) needed to be situated within thicker, more capacious attention to the 'social' than was then on offer.

We came to believe, as we pursued this intuition, that the increasingly formalized space of 'interdisciplinarity' between the life sciences, the social sciences, and the humanities, which we saw being assembled, was not necessarily a boon to attempts to think the 'bio' and the 'social' together. This space of interdisciplinary research on the mind and 
brain was becoming, in fact, a significant problem in its own right. This volume is our attempt to think about that problem. We are interested, here, not so much in providing a theoretical analysis (we have done this elsewhere; see e.g. Fitzgerald and Callard 2015), nor in providing a history of the numerous efforts to create interdisciplinary domains or disciplines within and across the sciences, social sciences, and humanities (see e.g. Graff 2015). Instead, we treat the emergence of this space the space of 'interdisciplinarity' as it engages the neurosciences, social sciences, and humanities - as a historical and sociological artefact, an object that offers numerous openings as well as constraints. Working through our own memories, reflections, and feelings from the last five years or so, we ask: What is this space? What forms of practice and ethics does it call us towards? What holds it together? What have its various analysts not told us? How does it end up deadening and closing down possibilities, even as it abounds in affirmations of its innovativeness and creativity? And how, if it really is as problematic as we think it is, might it be reimagined and practised differently? What, we ask, would a delicate, difficult, transgressive, risky, playful, and genuinely experimental interdisciplinarity involving neuroscientists, social scientists, and humanities scholars actually look like? And what, moreover, might it be able to achieve?

Interdisciplinarity is a term that everyone invokes and none understands. We have lost track of the number of articles, broadsides, reports, and monographs that we have read that have variously defined, championed, dissected, and excoriated interdisciplinarity. 'Interdisciplinarity has come to be', Andrew Barry and Georgina Born rightly note, in an unusually substantial analysis of the logics of interdisciplinarity, 'at once a governmental demand, a reflexive orientation within the academy and an object of knowledge' (Barry and Born 2013, 4). What follows springs from our deep dissatisfaction with much of what passes as 'interdisciplinarity' - both in theory and practice. Its arguments are built from our immersion, over many years, in reading, writing about, and practising many forms of interdisciplinary research. Along the way, we have become increasingly irritated with the normative weight that that this prefix - inter- - has come to carry. A kind of transgression is apparently achieved by working between one discipline and another - and yet fundamental assumptions (e.g. about what an experiment might be, about who does it, about how its objects are produced, and so on) are left quite unquestioned. We have been repeatedly struck by how profoundly 
uninteresting - and how conservative - much self-described interdisciplinary scholarship and practice actually is.

We are committed to the view that the particular arena with which we're concerned deserves better than much of the 'interdisciplinary' research that has taken place around it. That arena comprises minds, brains, bodies - as well as, crucially, their relations with what the neurologist and psychiatrist Kurt Goldstein described as an organism's milieu (namely, 'that part [of the world] that is adequate to it, that is, that allows for the described relationship between the organism and its environment' (Goldstein 1995 [1934], 106)). There have been a number of overtures from 'the neurosciences' vis-à-vis the need to engage with 'the social sciences' - and, simultaneously, many social scientists and humanities scholars who have engaged with neuroscientists. But there are strikingly few examples of research involving both neuroscientists and social scientists that have managed to avoid simply acceding to the epistemological and methodological demands of one half of the dyad. And this 'interdisciplinary science' is not going to disappear any time soon. So there are potent intellectual and practical reasons that underpin the arguments we make for new ways of thinking about and undertaking interdisciplinary research.

At the same time, we - in collaboration with many others - have, for a number of years, struggled to develop modes of thinking and practice that do something slightly different in that same space, without obviating the inequalities (see Chapter 6) and complex emotional demands (see Chapter 7) that characterize the terrain on which interdisciplinary social scientific and neuroscientific research takes place. Our book is also an attempt to make sense of those efforts for a broader audience: we want to present, for wider discussion, some of those modes of collaborative thinking and practice. And we want to be honest, for once, about what interdisciplinarity actually looks and feels like - certainly in terms of the often challenging day-to-day realities that people from all disciplinary backgrounds experience when they live 'between' disciplines, but also in terms of the modes and practices through which we, in collaboration with others from other disciplines, have been able to open up some interesting research directions and problems that address the 'bio' and the 'social' simultaneously (see Chapters 2 and 4 ). We hope that we might pique others' curiosity, and even widen their potential repertoires, either as they enter this terrain for the first time, or as they persist with long-standing interdisciplinary collaborations. 
We remain convinced that there are many more research questions in this problem-space to be burrowed into, and opened up. This is important not only for reasons of intrinsic interest, but because this terrain - comprising minds, brains, and their environments - encompasses many of the most pressing societal questions of our age. These include, but are not limited to: how to attend to mental distress and psychopathology as phenomena that bring the neurological, psychological, psychopharmacological, and sociological together in deeply complex ways; how to understand the ways in which particular social phenomena and social relations (such as poverty, urban living, familial dynamics, migratory patterns) are entangled with physiological and neurological differences; and how to unpick, and expand, the dense histories and debates that are built into the neurobiological and psychological models through which many people today understand themselves - through which, indeed, they have come to be understood. We add the proviso that much of the book focuses more on how to conceptualize some of these problems, and how to design and analyse the means through which collaborative research across the social sciences and the neurosciences might best tackle them, than on reporting extensive outcomes of interdisciplinary research that we have (already) completed to advance those particular research areas. The book is, in many ways, a 'report from the field'.

The modes of thinking and working that we consider in this volume have been strongly inflected by particular arrangements of institutions, funders, and cross-disciplinary debates. We are able to discuss, analyse, critique, and propose various configurations in this volume only because of the prior and contemporaneous labours of a significant number of individuals who have, for many years, been tinkering with, advocating, and bringing into being opportunities for collaboration across the mind and brain sciences. While this book does not present a history of interdisciplinary collaborations in this arena, we are very aware of the pioneers and fellow travellers whose endeavours have, to a significant extent, underpinned our own enquiries, and we provide some additional details about these people, organizations, and funders in Chapter 1. Together, these have characterized the space of early twenty-first century 'interdisciplinary' research about the mind and brain. And so we also understand this volume as a set of reflections that will - in time - perhaps become part of the archive of a specific moment in the history of the human sciences. 


\section{Experimental entanglements}

Some of you might well have been told, as we both have been variously told, by your mentors, supervisors, university, or research institute, that interdisciplinarity is the future. If you have received that message, it might well have generated a variety of emotions in you, and we are certainly not assuming that all of them will have been positive. But if everyone seems to be talking about interdisciplinarity, it's far from clear how many are actually doing it, and, if so, to what effect. Accounts of what interdisciplinary projects are like in practice are still relatively few in number, and most people are still reticent about the quotidian experiences that characterize them. There are especially few accounts of occasions in which social scientists and humanities scholars have been experimenters alongside scientists (though see Lane et al. 2011 for an account of an experiment in which knowledge regarding flooding was co-produced across these domains; see also Rabinow and Bennett 2012).

Of course, the neurosciences are themselves already a profoundly interdisciplinary endeavour (which brings together biology, chemistry, physics, cognitive science, computer science, engineering, mathematics, neurology, genetics, and psychology) (Adelman 2010; Rose and Abi-Rached 2013). When one refers, then, to a neuroscientist, one might be referring to someone with a background in physics or mathematics or psychology or philosophy (to name just a few). When we talk about the neurosciences in this volume, we are largely referring to cognitive neuroscience (i.e. the field that addresses the relationship between mental/cognitive functions and the brain, often using different brainimaging techniques). There are also numerous ways of practising 'interdisciplinarity' (though we suggest that oftentimes what results is actually 'multidisciplinarity') via the bringing together of researchers who share broadly similar epistemological starting points. (For example, health services research often involves clinical researchers, positivistic quantitative and qualitative social scientists, health economists and statisticians; collaborative projects in the humanities and social scientists might involve historians, cultural studies scholars, and literary theorists.) But what we're talking about here is what we believe to be a more fractious kind of interdisciplinarity. This is one that brings together epistemological and ontological domains - within and across the life sciences, interpretive social sciences (those that depart from positivistic social sciences in their commitment to some kind of hermeneutic analysis; see 
Geertz 1973) and the humanities - that are often more profoundly split, one from the other, than the interdisciplinary configurations mentioned above. In making this claim, we are not forgetting the profound internecine battles that have coursed within and across disciplinary subfields, as well as between disciplines thought to be relatively similar to one another. (Some examples would include relations between social and biological anthropologists, or controversies between Continental and analytic philosophers.) We are also not forgetting that there has been a long tradition of natural scientists (e.g. those within biological psychiatry) working alongside (mostly) positivist social scientists. Throughout this book, though, when we refer to 'interdisciplinarity', we are focused particularly on collaborations that bring together life scientists, interpretive social scientists and humanities scholars.

Our inhabitation of that fractious space has led to our development of what we call 'experimental entanglements' - which is our name for approaching the densely patterned terrain of research on the mind and brain, as well as for the specific interventions (experimental in all senses of that word) that we carry out under its umbrella. We will not belabour the point here (it is belaboured in Fitzgerald and Callard 2015; Fitzgerald and Callard forthcoming), but 'experimental entanglements' depart from a logic of the 'inter-', which presumes that there are two kinds of preexisting things (e.g. the natural sciences and social sciences), which may or may not be integrated, and/or which may be integrated more or less well. If we are at all to make good on the current promise of interdisciplinarity, we must stop pinioning people, dead-butterfly-like, into particular slots within disciplinary taxonomies - slots, moreover, that depend on intensely misunderstood histories of (in the broadest sense) scientific inquiry itself, as well as the various intellectual practices, motivations, and affects that have only lately been distributed around the arrangements that today call themselves disciplines. Such pinioning also depends on a strikingly naive view of the actual things of the world; as if people had bits that were distinctively social, and bits that were distinctively natural - as if they were not, in fact, endlessly torqued concatenations of disposition and agency, both human and non-human, and vague, halfglimpses of which we have only recently decided to encumber with the inadequate terms 'biological', 'social', 'psychological', and so on.

If this begins to look suspiciously like metaphysics, we stress that our concern is for the practical consequences that ensue when the 'biological' and 'social' are separated out, one from the other. To this we attribute, 
for example, the ease with which the social sciences, humanities, and the arts come simply to contextualize or illustrate scientific research; or the bizarre separation of powers that sees something like 'bioethics' as a practice that might only comment on, and not produce, the 'biosciences'. Our desire radically to depart from such an approach drives our interest in experiment in all its guises. Experiment, as we have elaborated elsewhere (Fitzgerald and Callard 2015), has multiple genealogies. For us, experimental theatre and experimental poetry promise as much - in terms of methods, knowledges, modes of construing, and intervening in the world - as the rich legacy of experimentation in the natural sciences (Roepstorff and Frith 2012). Experiments, moreover, take place as much in the relationships that unfold between collaborators, in the interventions that they choose to make in their respective fields, in the various ways that historical archives might be reopened, as much as they do in regular scientific protocols to produce new data (see e.g. Blackman 2014). We are not naïve about the profound differences between 'experiment' as it operates in the arts and as it has been conducted in the laboratory sciences. We acknowledge that the problem-spaces opened up within the pages of a novel offer different affordances from those characterizing all manner of scientific experiments (see, in this respect, Waugh 2015). Nonetheless, we think there is more work to be done to explore how different ways of being 'experimental' can open up new avenues through which to think and work collaboratively across distinct arenas of expertise.

Rethinking Interdisciplinarity across the Social Sciences and Neurosciences was written in a particular, and decidedly partial, mode. The book is not intended as a definitive account even of our own efforts at interaction and collaboration. We know well that many will disagree with us. Still less do we wish this volume to be read as a grand statement about interdisciplinary work as such. Our desire to bring this account into the world is motivated precisely by our shared sense that the declarative mode is perhaps not well suited to the strange labours of collaboration. In the on-going, global 'workshop' of interdisciplinary thought, what follows is rather less a pronouncement from a stage - and rather more an odd, out-of-step, perhaps slightly querulous, contribution from the floor. In this regard, we see the book, too, as an experiment in scholarly production. The Pivot format is produced within a distinctive (rapid) temporal horizon, and offers a particular length (mid-way between the long journal article and the usual scholarly monograph). We, when 
writing this volume, were interested in exploring what those constraints would do to our modes of argument, to the register of our writing, and to the kinds of material with which we engaged. The book works with, and mixes up, different kinds of 'data' and evidence, and employs diverse styles of argument. Our hope is that the volume functions as a provocation that carries a particular tone - one slightly different from the usual 'voice' of a peer-reviewed journal article (from whichever discipline), or of a heavily footnoted research monograph. It emerged out of our own, various kinds of discomposure in relation to the interdisciplinary field of our enquiries. It might, in turn, effect discomposure in some of its readers. Rethinking interdisciplinarity, we contend, can't avoid that risk.

\section{The view from nowhere}

This book is for anyone who has been urged to do something in an interdisciplinary way (whether that urge has come from external pressures, or seems to have come from within him or herself, somewhere) - and who has wondered, exactly, what this word 'interdisciplinary' entails. It is for anyone who has already been involved in an interdisciplinary project - who has experienced some unexpected bumps in the road, and who has been wondering how to understand those bumps, and work around them in the future. And it is for anyone, from any background, and at whatever career stage, who has some inkling that there is a perspective from another discipline that might really open one of their own projects, but who has no idea how to do something with a colleague from that discipline, and even less idea of what such a collaboration might actually look like. As we have already noted, we will be especially concerned here with interactions between (interpretive) social scientists and neuroscientists, but the broader lessons and claims of the book should be as applicable to a researcher interested in interdisciplinary molecular genetics, or, indeed, a cognitive neuroscientist interested in working with a computational neuroscientist. Threaded through all the chapters, and for readers of all stripes, we have included a series of 'Notes \& Queries' - a collection of short and frank answers to pragmatic questions, which will guide the reader through issues such as how one actually assembles an interdisciplinary team, gets involved in collaborative projects, manages the dynamics of interdisciplinary team interaction, and so on. 
One of the founding premises of this volume is that there is no 'view from nowhere' for conceptualizing, investigating, and writing about brains, minds, bodies, and their environments. Different modes of investigation carry with them different archival legacies, and conventions of thinking and writing. As any theorist of translation, or historian of science will know all too well, there is no straightforward, translucent 'language' through which any of us can present research findings, let alone arguments. As much as we want to trouble a model of disciplines in which each is confined to her own pen, let us stress that this book is written, unapologetically, by two authors who have been trained in different corners of the interpretive social sciences, and who ally themselves with social and cultural theory. Having spent significant amounts of time and resources training ourselves up in cognitive neuroscience, as well as working closely with neuroscientists, we consider ourselves to be - as social scientists go - relatively well versed in the neurosciences, and in the rhetorics through which those sciences move forward. We will do all we can to speak to, through, and with those rhetorics in what follows. Nonetheless, we do have particular networks of citations, modes of address, and means of presenting and analysing our interlocutors' arguments and empirical materials. This will provoke discomfort in some of our readers and friends steeped in other, scientific traditions for writing, and thinking and reading. But this, in many ways, is a volume about learning to be discomfited.

\section{How to ruin your career}

'Interdisciplinary Research: Why It's Seen as a Risky Route' runs the headline in The Guardian. The author, a doctoral student in the natural sciences, but one who crosses into several different areas, cogently sets out the reasons why being (or being seen to be) 'interdisciplinary' can mean facing 'an uncertain future' (Byrne 2014). The problem, the student points out, is the mismatch between institutional eulogies for the interdisciplinary, and the antediluvian structures of advancement and prestige both within and outside those same departments - journals, funding councils, adjudications of teaching expertise - that split resolutely along disciplinary lines. 'Trying to gain expertise and familiarity with the literature in multiple subject areas can be a discouraging and near-impossible task,' she points out: 'There's a risk of ending up being an expert in nothing' (Byrne 2014). Those most at risk from this mismatch, the author points out, are people at relatively 
early stages in their careers - who need to be able to demonstrate highly disciplined forms of value in order to secure a coveted permanent post.

We have come across - and indeed have ourselves voiced - many such fears in the past. And we take these concerns seriously. We would add to them our own career-related worries, which include the fear that one will be ignored or dismissed (not least if one's publications are highly dispersed across a number of disciplinary journals and books). Particularly for junior people who are actively on the job market, there seems little premium in appearing deviant from the norm. For such researchers, there is a constant, nagging anxiety: by following my interests into some strange places; by publishing in journals that have little name recognition to senior people in my field; by seeking grants with those who are positioned significantly beyond my own discipline; by slowing down my usual rate of publication by dint of spending time developing strange collaborative research with researchers who need explanations of some of the key concepts and methods in my field; and in general by positioning myself as not just orthogonal to, but very much against, what looks like 'normal science' or 'normal research' - am I (without pushing to over-dramatize the situation) effectively ruining my career? Nor are we persuaded by the bureaucratic emollient that is usually spread over such concerns. The reality is that the markers of prestige in the academy, however much managers may wish them otherwise, remain suspicious of deviance.

But the thing is: we and our dispersed network of collaborators haven't ruined our careers. Through this book, then, we want to dispel, or at least to dial down, two recurring thoughts that structure interdisciplinary research. One, as above, is the thought that being interdisciplinary is inherently risky - that, if you are not careful, you will fall between stools, have your work be ignored, and be seen as a 'jack of all trades'. This generally held position is not ridiculous, but it is, we believe, overemphasized. The reality is that, even if the old markers of achievement remain (the single-authored article in Transactions of the Institute of British Geographers has not yet lost its lustre for geographers, nor the first authored article in Proceedings of the National Academy of Sciences for neuroscientists), the reality is that more and more editors, research managers, heads of school, and other gatekeepers are explicitly looking for people - in the humanities and social sciences as well as in the sciences - who have expertise in interdisciplinary, collaborative projects. The risks of interdisciplinarity aren't what they used to be.

The second thought we want to dispel is the mirror-image of this one, which is that caution betokens staying within the bounds of disciplinary respectability. The more we wander down strange interdisciplinary tracks, 
the more apparent it becomes to us that being disciplined isn't playing it safe: the truth is that staying within the narrow epistemological confines of - for example - mid-twentieth-century sociology, while it may produce short-term gains, is not, in fact, the best way to guarantee a career in the twenty-first century (and we mean 'career' in its most capacious sense here: we are not using it with the assumption that everyone wants a permanent post at a university, but to express an idea that many would like to find some way to advance their projects, ideas, and so on). The plate tectonics of the human sciences are shifting: we here describe our own forays into one small, circumscribed niche between the social and natural sciences, but expand this horizon to epigenetics, to the emergence of the human microbiome, to all kinds of translational research in mental health, to 'big data' and the devices that append it, to the breakdown of the barrier between creative practices and research, and to a whole host of other collapsing dichotomies, and it becomes apparent that 'neuro-social science' is only one local effect of a much broader reverberation. Despite everything that follows in the book, we remain excited by such movement. And if cracks are emerging that we - and our collaborators - might yet fall through, still the two of us, at least, are determined to go into them facing forward. This monograph is therefore part of the archive of one moment, when those same cracks started to appear - and when it seemed to us, and to many of our collaborators, like a good idea to try to work our way into them. Our hope is that it helps to create room for similar reflections in this same space - and even that such reflections will go on to effect similar reverberations of their own.

This volume comprises, as we imagine is pretty clear by now, a partial account. It traces journeys that we - both singly and together - have taken, since 2008, through the bizarre world of interdisciplinary research that addresses the mind and brain. We have written it in the midst of our other research within 'Hubbub', a large interdisciplinary project (which crosses the neurosciences, mind sciences, social sciences, humanities and the arts) that we take up in greater detail in Chapter 4. As we have pieced the book together, we have increasingly imagined that the book might be read - by some at least - as a strange version of the picaresque novel. The genre of picaresque is characterized by a dishonest but agreeable picaro who drifts from one locale to another and immerses himself in the vagaries of different social milieux in his efforts to survive. Such a description could well be said to characterize our inhabitation - sometimes chosen, 
sometimes un-willed - of various socio-technological worlds in several countries, many cities, and alongside many individuals who have become personages, characters, and, often times, our friends. And if picaresque fiction narrates adventures in an episodic manner, leaves certain things out, and is not always clear about the epistemological robustness, let alone rectitude, of its protagonist's intentions and actions, then this volume is, we hope, a decent imitation of the genre. We include stories that incorporate the reported speech of some of the aforementioned characters, and we anatomize the emotional timbre of both their and our journeys through these spaces. No story has been invented (though each has been filtered through one or both of our memories, rather than attempts to do justice to the memories of all those involved). Identifying details have been excised or changed (unless permission has been granted from the person invoked to use that person's name). The book is built on the back of those affectively freighted stories. The experiences from which they arose told us much more about interdisciplinarity than the many books we read before and during our life spent in the interdisciplinary field.

'Every discipline tells a story', notes the historian of science Simon Schaffer: 'where it comes from, what it is and where it is going. Disciplines learn such parables as part of their induction' (Schaffer 2013, 57). The range of parables about interdisciplinarity is distinctly narrow: most of them have tended to send both of us to sleep. We hope in the episodes that follow at least to keep you awake. 'A sociologist collaborating with a human geographer', noted a commentator on interdisciplinarity recently, 'is scarcely likely to generate as much excitement as an artist working with a scientist' (Osborne 2013, 95). Well, the constraints of genre are such that we don't believe we can escape our disciplinary origins. Even the picaro has to come from somewhere. Let us try to convince you, nonetheless, through the labour of our collaborations - as a human geographer and sociologist - with many others from multiple disciplines - that there are forms of interdisciplinary practice that, even if only occasionally, even if sometimes fractious, even if freighted with all the worries and anxieties that we are going to set out below, even if they sometimes fall apart, are still sometimes epistemologically and interpersonally exciting.

Except where otherwise noted, this work is licensed under a Creative Commons Attribution 3.0 Unported License. To view a copy of this license, visit https://creativecommons.org/licenses/by/3.0/ 